\title{
Genetic susceptibility of early aseptic loosening after total hip arthroplasty: the influence of TIMP-1 gene polymorphism on Chinese Han population
}

\author{
Fengyu Pan ${ }^{1 *}$, Shan Hua ${ }^{2}$, Yi Luo $^{1}$, Dongjun Yin ${ }^{1}$ and Zhuang Ma ${ }^{1}$
}

\begin{abstract}
Objective: Genetic factor plays an important role in early failure of total hip arthroplasty (aseptic loosening) etiology, and TIMP-1 gene may be involved. The present study was conducted to reveal possible association between TIMP-1 polymorphisms with the risk of early failure of total hip arthroplasty (THA) (aseptic loosening).

Methods: The TIMP-1 single nucleotide polymorphisms (SNPs) rs4898, rs6609533, and rs2070584 were genotyped in 59 subjects who were diagnosed as aseptic loosening after total hip arthroplasty and in 100 controls.

Results: The TIMP-1 SNP rs4898 T allele in the case group was found to be 1.32 fold $(P=0.0013,95 \% \mathrm{Cl}=1.16$ to 1.58) than the control group. Similarly, the $G$ allele of rs 6609533 was found to be associated with increased risk of aseptic loosening $(\mathrm{OR}=1.78,95 \% \mathrm{Cl}=1.52$ to $2.17, P<0.0001)$. For SNP rs2070584, no statistical association was found (A vs. $G, O R=1.14,95 \% \mathrm{Cl}=0.97$ to $1.40, P=0.2028$ ).

Conclusion: The results showed that the TIMP-1 SNPs rs4898 and rs6609533 were associated with the increased risk of early aseptic loosening susceptibility.
\end{abstract}

Keywords: Total hip arthroplasty, Genetic factor, Single nucleotide polymorphisms

\section{Introduction}

There are numerous patients with end stage arthritis treated with cemented total hip arthroplasty (THA), and the number is rapidly increasing [1-4]. Almost 1 million of THA are implanted worldwide annually, with a predicting increase of $174 \%$ to nearly 600,000 THA procedures annually by 2030 in the United States [5-7]. However, indispensable proportion of patients after THA still faces the complications that may lead to the premature prosthesis failure and revision surgery, with significant impact on their quality of life [5]. While sepsis, fracture, and dislocation are relatively rare, loosening of the total hip prosthesis arising from aseptic inflammatory reactions is one of the most critical phenomena (accounts for $75.7 \%$ of all THA revisions) in the treatment of total hip arthroplasty [8-10].

\footnotetext{
* Correspondence: fypan_2014@163.com

'Department of Orthopaedics, Chinese People's Liberation Army 107

Hospital, No.7 South Zhichu Road, Yantai 264002, China

Full list of author information is available at the end of the article
}

The aseptic loosening after THA has been considered to be due to both mechanical stress and local host responses to the implanted materials including the wear debris of high density polyethylene, bone cement, and metals; however, the precise biological mechanisms responsible for loosening have not yet been completely clarified [11-14]. Nowadays, it is considered that the prosthesis stimulates the inflammatory response of mesenchymal cells and accumulates the osteoclast, leading to excessive resorption, bone loss, and eventually periprosthetic osteolysis $[15,16]$. However, given the existence of the individual difference of susceptibility to aseptic loosening, there may be a combination of environmental and genetic factors influencing the pathologies. Environmental factors have been widely studied across the world, including the implant design, material, type of prosthesis, fixation method, surgical technique, and postoperative rehabilitation procedure $[17,18]$. However, the individual susceptibility difference was mostly related to the genetic factors like single nucleotide polymorphisms (SNPs). Various gene SNPs of GNAS1, 
TNF-238, TNF-a, IL6-174, MMP1, MMP2, etc. were reported to be associated with increased prosthetic loosening.

The release of implant particles and debris into the periprosthetic tissues leads to the formation of reactive granulation tissue against a foreign body, and it activates the cells to produce cytokines and enzymes [19]. Previous studies demonstrated that this granulomatous tissue has the ability to produce inflammatory cytokines and substances, i.e., interleukin-1 (IL-1), platelet-derived growth factor (PDGF), prostaglandin E2 (PGE2), etc. [20]. Matrix metalloproteinases (MMPs) are a family of enzymes secreted by mesenchymal and haemopoietic cells that can degrade various types of collagen, which is the most important component of the extracellular matrix (ECM). They are active at neutral $\mathrm{pH}$ and are all inhibited by specific secreted inhibitors, tissue inhibitors of metalloproteinases (TIMPs). Recently, many studies acknowledged that MMPs play an important role in the variety of tissue destruction, i.e., metastatic tumor, rheumatoid arthritis, and cartilage breakdown [21]. Numerous studies have demonstrated that specific MMPs and TIMPs are expressed in the periprosthetic tissues and are critically involved in the bone resorption and subsequent implant failure [22-27]. SNPs of MMP1 have been related to increased risk of prosthetic loosening. However, no genetic research between TIMPs polymorphism and aseptic loosening after THA has been performed so far. This study aims to determine whether the TIMP-1 SNPs rs4898, rs6609533, and rs2070584 were associated with failure of THA (aseptic loosening) in Chinese Han population.

\section{Method}

The study was approved by the ethics committee of the Chinese People's Liberation Army 107 Hospital, and informed consent was obtained from patients and control participants.

\section{Study population}

Fifty-nine patients diagnosed with aseptic loosening after total hip arthroplasty at the Department of Orthopaedics of Chinese People's Liberation Army 107 Hospital were enrolled in this study. All the patients were diagnosed based on the findings of clinical, radiological, laboratory, and intra-surgical changes. The diagnosis criteria of aseptic loosening were documented as follows: 1. Clinical symptoms like hip pain during walking or moving the joint. 2. Radiological changes like migration of prosthetic or bone radiolucency around the prosthesis of more than $2 \mathrm{~mm}$. 3. Abnormal laboratory data like erythrocyte sedimentation rate and leukogram. Patients were excluded if they had any deep infection or the suspicion of implant infection, inflammatory diseases, traumatic loosening, or immunosuppressant agents after THA in their history. Also, aseptic loosening developed after 10 years since THA was excluded from this study. The control group consists of 100 age- and gendermatched patients who had undergone THA that had been seen to be therapeutically successful over longterm follow-up. All subjects included in this study were Chinese Han population.

\section{Genotyping}

DNA samples were obtained from all the participants from peripheral blood with the Chelex 100 method [28]. The primers and probes were designed and synthesized by Sigma (Sigma-Proligo, The Woodlands, TX). The SNPs were genotyped using Taqman assay (Applied Biosystems 7500, ABI, Foster City, CA) and dual-labeled probes in real-time PCR. Genotyping was performed by an independent laboratory personnel, and two authors independently reviewed the results. Disagreements were resolved through a discussion and consensus. In addition, $5 \%$ samples of the case and control subjects were randomly selected for reproducibility tests at least twice to yield a $100 \%$ concordant.

\section{Statistical analysis}

Statistical Package for Social Sciences software (SPSS Inc., Chicago, IL, USA), version 16.0 for Windows and HaploView software were used for statistical analysis in this study. The demographic and clinical data were presented as mean \pm SD and compared between groups by the student's $t$ tests. The genotype and allelic frequencies were evaluated by Hardy-Weinberg equilibrium and compared by the Chi-square test. Multivariate logistic regression was used to estimate odds ratios (ORs) and 95\% confidence intervals (CI) after adjustment for age, gender, and body mass index (BMI). The linkage disequilibrium (LD) mapping and the associations between haplotypes of selected SNPs and risk of aseptic loosening after THA were estimated by HaploView software. The $P<0.05$ was considered to indicate a statistically significant difference.

\section{Results}

\section{Patient characteristics}

Demographic data of the subjects enrolled were shown in Table 1. There were no significant differences between groups in respect to the age, gender, and BMI. The mean period after THA was $8.2 \pm 1.5$ years when the aseptic loosening happened, and the control group has a mean period of $12.7 \pm 2.3$ years after THA.

\section{Association of TIMP-1 polymorphisms with susceptibility to failure of THA}

As expected, the distribution of the genotypes of SNPs of TIMP-1 gene conformed to the Hardy-Weinberg equilibrium and the genotyping success rate was $100 \%$. 
Table 1 The summary of the basic characteristics of the groups

\begin{tabular}{llll}
\hline Clinical characteristics & $\begin{array}{l}\text { Aseptic loosening } \\
\text { patients }\end{array}$ & Controls & $\boldsymbol{P}$ value \\
\hline Number & 59 & 100 & \\
Age (years) & $68.6 \pm 8.4$ & $70.3 \pm 7.1$ & n.s \\
Female/male & $22 / 37$ & $36 / 64$ & n.s \\
BMl (kg/m ${ }^{2}$ ) & $27.4 \pm 5.9$ & $26.9 \pm 6.6$ & n.s \\
Mean time after THA (years) & $8.2 \pm 1.5$ & $12.7 \pm 2.3$ & $<0.001$ \\
\hline
\end{tabular}

Table 2 listed the genotyped and allele distributions of the three SNPs for the cases and controls. The TIMP-1 SNPs rs4898 and rs6609533 were found to be significantly associated with an increased risk of THA failure after adjustment of age, gender, and BMI. The TIMP-1 SNP rs4898 $\mathrm{T}$ allele in the case group was found to be 1.32 fold $(P=0.0013,95 \% \mathrm{CI}=1.16$ to 1.58$)$ than the control group. Similarly, the G allele of rs6609533 was found to be associated with an increased risk of aseptic loosening $(\mathrm{OR}=1.78,95 \% \mathrm{CI}=1.52$ to $2.17, P<0.0001)$. For SNP rs2070584, no statistical association was found (A vs. $\mathrm{G}, \mathrm{OR}=1.14,95 \% \mathrm{CI}=0.97$ to $1.40, P=0.2028$ ).

The LD within TIMP-1 gene was only found between rs4898 and rs6609533, showing that these two polymorphisms belong to one haploblock (Figure 1).

\section{Discussion}

This is the first study investigating the possible role of TIMP-1 SNPs in the pathologies of aseptic loosening of the total hip prosthesis. The present study revealed the association between TIMP-1 SNPs rs4898 and rs6609533 with the increased risk of early failure of THA (aseptic loosening).

Table 2 The genotype and allele distributions of the three SNPs for the cases and controls

\begin{tabular}{|c|c|c|c|c|c|c|c|}
\hline \multirow[t]{2}{*}{ Group } & \multicolumn{3}{|c|}{ rs4898 Genotype } & \multicolumn{4}{|c|}{ Allele (\%) } \\
\hline & $\mathrm{CC}$ & CT & $\mathrm{TT}$ & $\mathrm{C}$ & $\mathbf{T}$ & OR $(95 \% C l)^{a}$ & $P^{a}$ \\
\hline Control & 36 & 45 & 19 & 58.5 & 41.5 & $1.32(1.16$ to 1.58$)$ & 0.0013 \\
\hline Case & 16 & 29 & 14 & 51.7 & 48.3 & & \\
\hline \multirow[t]{2}{*}{ Group } & \multicolumn{3}{|c|}{ rs6609533 Genotype } & \multicolumn{4}{|c|}{ Allele (\%) } \\
\hline & $\pi$ & $\mathrm{TG}$ & GG & $\mathrm{T}$ & G & OR $(95 \% C l)^{a}$ & $p^{\mathrm{a}}$ \\
\hline Control & 45 & 37 & 18 & 63.5 & 36.5 & 1.78 (1.52 to 2.17 ) & $<0.0001$ \\
\hline Case & 13 & 32 & 14 & 49.2 & 50.8 & & \\
\hline \multirow[t]{2}{*}{ Group } & \multicolumn{3}{|c|}{ rs2070584 Genotype } & \multicolumn{4}{|c|}{ Allele (\%) } \\
\hline & GG & $A G$ & AA & G & A & OR $(95 \% C l)^{a}$ & $p^{a}$ \\
\hline Control & 49 & 40 & 11 & 69.0 & 31.0 & 1.14 (0.97 to 1.40$)$ & 0.2028 \\
\hline Case & 27 & 24 & 8 & 66.1 & 33.9 & & \\
\hline
\end{tabular}

${ }^{\mathrm{a}}$ ORs and $95 \% \mathrm{Cls}$ were estimated using multiple logistic regression analyses and adjusted for age, gender, and BMI.

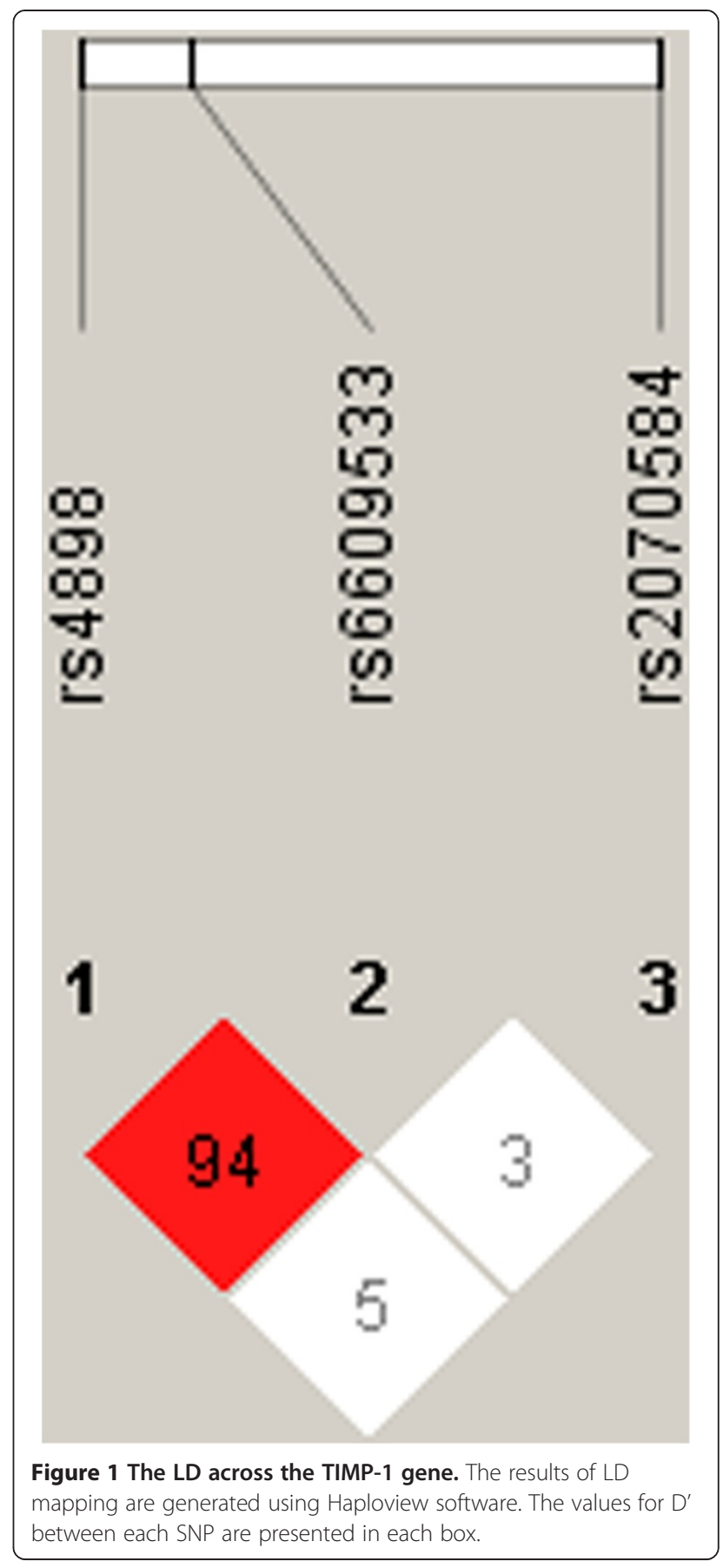

Although total hip arthroplasty is a mature and successful surgery that improves the quality of life significantly, it cannot be ignored that there are still many patients suffering from early failure of the THA. Importantly, aseptic loosening due to the periprosthetic osteolysis is known to be the main reason for an early failure after THA.

Although many reports have been published on the pathogenesis of periprosthetic loosening, the precise biological mechanisms responsible for this process have not 
yet been completely elucidated. Biological, microbiological, biomechanical factors, etc. have been considered to introduce the aseptic loosening. However, the abnormal immunological responses caused by the wear-generated particular debris surrounding the implant components were considered as the core of the pathologies $[29,30]$. The periprosthetic loosening and osteolysis were found to be correlated with higher wear rates of the prosthesis [29]. The experimental systems also demonstrated that particulate debris could induce osteolysis in a variety of animal models and inflammatory responses in cultured macrophages [31,32]. The release of particles induced an immunological response which is taking place in the capsular tissue initially. The macrophages, osteoclasts, fibroblasts, etc. were activated and produced various chemical factors and mediators [17,33-36]. These soluble factors migrate in the interface between the implant and the bone, where they continue the immune response but mainly affected the bone tissues.

ECM degradation and connective tissue remodeling around implants have been considered as major biological events in the periprosthetic loosening. Among which the MMPs and TIMPs play as critical mediators of wear particle-induced inflammatory osteolysis. MMP is one of the cytokines and lipid mediators that increases the destruction of the extracellular organic matrix of bone [22,23,37-39]. The expression of MMP-13 was found in the macrophages, endothelial cells, and fibroblasts of the synovial-like membrane around the implant [35]. Local messenger RNA (mRNA) expression profile also showed that MMP-1, MMP-9, MMP-10, MMP-12, and MMP-13 were strongly elevated in aseptic loosening compared to controls. Furthermore, collagen degradation in periprosthetic tissue correlated significantly with the number of local MMP-1 and MMP-13 [36]. Recently, Malik and coworkers reported the association of a MMP-1 SNP rs5854 and the occurrence of increased aseptic loosening susceptibility [40]. The proteolytic activity of MMPs is regulated by specific TIMPs. The balance between the levels of activated MMPs and free TIMPs determines in part the net MMP activity. In addition to regulating the MMPs, TIMPs have also been shown to have angiogenic and growth factor-like activities [41]. Quantitative analysis of mRNA expression of TIMPs in periprosthetic tissues showed a significant upregulation of TIMP-1, TIMP-2, and TIMP-3 in contrast to the decreased levels of TIMP-4 [25]. The strong expression of TIMP-2 in the interface tissue around implants was also reported by Ishiguro and coworkers [26].

The most important limitation of the present study is the relatively small sample size. A single center casecontrol study is not sufficient to fully interpret the relationship between TIMP-1 polymorphisms and the risk of early failure of THA (aseptic loosening). Further study with multiple center and larger sample size is needed. Also, our investigation is only a genetic association study, and the precise impact of this polymorphism on protein function has not been confirmed by molecular biology techniques.

\section{Conclusions}

The present study was conducted to reveal possible association between TIMP-1 SNPs with the risk of early failure of THA (aseptic loosening). The results showed that the TIMP-1 SNPs rs4898 and rs6609533 were associated with the increased risk of early aseptic loosening susceptibility.

\section{Competing interests}

The authors declare that they have no competing interests.

\section{Authors' contributions}

FP carried out the molecular genetic studies, participated in the sequence alignment, and drafted the manuscript. SH participated in the design of the study and performed the statistical analysis. YL participated in the design of the study and performed the statistical analysis. DY participated in the sequence alignment. ZM conceived of the study, participated in its design and coordination, and helped to draft the manuscript. All authors read and approved the final manuscript.

\section{Author details}

${ }^{1}$ Department of Orthopaedics, Chinese People's Liberation Army 107 Hospital, No.7 South Zhichu Road, Yantai 264002, China. ${ }^{2}$ Department of Radiology, Yantai Haigang Hospital, Yantai, Shandong, China.

Received: 19 September 2014 Accepted: 24 October 2014

Published online: 03 December 2014

\section{References}

1. Schwarzkopf R, Mikhael B, Wright E, Estok DM 2nd, Katz JN: Treatment failure among infected periprosthetic total hip arthroplasty patients. Open Orthop J 2014, 8:118-124.

2. Liu SS, Della Valle AG, Besculides MC, Gaber LK, Memtsoudis SG: Trends in mortality, complications, and demographics for primary hip arthroplasty in the United States. Int Orthop 2009, 33:643-651.

3. Ackerman IN, Graves SE, Bennell KL, Osborne RH: Evaluating quality of life in hip and knee replacement: psychometric properties of the World Health Organization quality of life short version instrument. Arthritis Rheum 2006, 55:583-590.

4. Barrett J, Losina E, Baron JA, Mahomed NN, Wright J, Katz JN: Survival following total hip replacement. J Bone Joint Surg Am 2005, 87:1965-1971.

5. Kurtz S, Ong K, Lau E, Mowat F, Halpern M: Projections of primary and revision hip and knee arthroplasty in the United States from 2005 to 2030. J Bone Joint Surg Am 2007, 89:780-785.

6. Crowninshield RD, Rosenberg AG, Sporer SM: Changing demographics of patients with total joint replacement. Clin Orthop Relat Res 2006, 443:266-272.

7. Buckwalter JA, Saltzman C, Brown T: The impact of osteoarthritis: implications for research. Clin Orthop Relat Res 2004, S6-S15.

8. Glant T, Jacobs JJ: Response of three murine macrophage populations to particulate debris: bone resorption in organ cultures. J Orthop Res 1994, 12:720-731.

9. Maloney WJ, Smith RL, Schmalzried TP, Chiba J, Huene D, Rubash H: Isolation and characterization of wear particles generated in patients who have had failure of a hip arthroplasty without cement. J Bone Joint Surg Am 1995, 77:1301-1310.

10. Mulroy WF, Harris WH: Revision total hip arthroplasty with use of so-called second-generation cementing techniques for aseptic loosening of the femoral component. A fifteen-year-average follow-up study. J Bone Joint Surg Am 1996, 78:325-330. 
11. Smith J, Lee D, Bali K, Railton P, Kinniburgh D, Faris P, Marshall D, Burkart B, Powell J: Does bearing size influence metal ion levels in large-head metal-on-metal total hip arthroplasty? A comparison of three total hip systems. J Orthop Surg Res 2014, 9:3.

12. Aspenberg P, Herbertsson P: Periprosthetic bone resorption. Particles versus movement. J Bone Joint Surg (Br) 1996, 78:641-646.

13. Maloney WJ, Smith RL: Periprosthetic osteolysis in total hip arthroplasty: the role of particulate wear debris. Instr Course Lect 1996, 45:171-182.

14. Vermes C, Kuzsner J, Bardos T, Than P: Prospective analysis of human leukocyte functional tests reveals metal sensitivity in patients with hip implant. J Orthop Surg Res 2013, 8:12.

15. Gallo J, Raska M, Mrazek F, Petrek M: Bone remodeling, particle disease and individual susceptibility to periprosthetic osteolysis. Physiol Res 2008, 57:339-349.

16. Goodman SB, Gomez Barrena E, Takagi M, Konttinen YT: Biocompatibility of total joint replacements: a review. J Biomed Mater Res A 2009, 90:603-618.

17. Gallo J, Kaminek P, Ticha V, Rihakova P, Ditmar R: Particle disease. A comprehensive theory of periprosthetic osteolysis: a review. Biomed Pap Med Fac Univ Palacky Olomouc Czech Repub 2002, 146:21-28.

18. Jacobs CA, Christensen CP, Berend ME: Sport activity after total hip arthroplasty: changes in surgical technique, implant design, and rehabilitation. J Sport Rehabil 2009, 18:47-59.

19. Chiba J, Schwendeman LJ, Booth RE Jr, Crossett LS, Rubash HE: A biochemical, histologic, and immunohistologic analysis of membranes obtained from failed cemented and cementless total knee arthroplasty. Clin Orthop Relat Res 1994, 114-124.

20. Jiranek WA, Machado M, Jasty M, Jevsevar D, Wolfe HJ, Goldring SR, Goldberg MJ, Harris WH: Production of cytokines around loosened cemented acetabular components. Analysis with immunohistochemical techniques and in situ hybridization. J Bone Joint Surg Am 1993, 75:863-879.

21. Woessner JF Jr: Matrix metalloproteinases and their inhibitors in connective tissue remodeling. FASEB J 1991, 5:2145-2154.

22. Takagi M, Konttinen $Y T$, Santavirta S, Sorsa T, Eisen AZ, Nordsletten L, Suda A: Extracellular matrix metalloproteinases around loose total hip prostheses. Acta Orthop Scand 1994, 65:281-286.

23. Takei I, Takagi M, Santavirta S, Ida H, Ishii M, Ogino T, Ainola M, Konttinen YT: Messenger ribonucleic acid expression of 16 matrix metalloproteinases in bone-implant interface tissues of loose artificial hip joints. J Biomed Mater Res 2000, 52:613-620.

24. Syggelos SA, Aletras AJ, Smirlaki I, Skandalis SS: Extracellular matrix degradation and tissue remodeling in periprosthetic loosening and osteolysis: focus on matrix metalloproteinases, their endogenous tissue inhibitors, and the proteasome. Biomed Res Int 2013, 2013:230805.

25. Sasaki K, Takagi M, Mandelin J, Takei I, Santavirta S, Ida H, Ogino T, Konttinen YT: Quantitative analysis of mRNA expression of TIMPs in the periprosthetic interface tissue of loose hips by real-time PCR system. J Biomed Mater Res 2001, 58:605-612.

26. Ishiguro N, Ito T, Kurokouchi K, Iwahori Y, Nagaya I, Hasegawa Y, Iwata H: mRNA expression of matrix metalloproteinases and tissue inhibitors of metalloproteinase in interface tissue around implants in loosening total hip arthroplasty. J Biomed Mater Res 1996, 32:611-617.

27. Syggelos SA, Eleftheriou SC, Giannopoulou E, Panagiotopoulos E, Aletras AJ: Gelatinolytic and collagenolytic activity in periprosthetic tissues from loose hip endoprostheses. J Rheumatol 2001, 28:1319-1329.

28. Walsh PS, Metzger DA, Higuchi R: Chelex 100 as a medium for simple extraction of DNA for PCR-based typing from forensic material. BioTechniques 1991, 10:506-513.

29. Dumbleton $\mathrm{JH}$, Manley MT, Edidin AA: A literature review of the association between wear rate and osteolysis in total hip arthroplasty. J Arthroplasty 2002, 17:649-661.

30. Schmalzried TP, Jasty M, Harris WH: Periprosthetic bone loss in total hip arthroplasty. Polyethylene wear debris and the concept of the effective joint space. J Bone Joint Surg Am 1992, 74:849-863.

31. Yang SY, Wu B, Mayton L, Mukherjee P, Robbins PD, Evans CH, Wooley PH: Protective effects of IL-1Ra or vlL-10 gene transfer on a murine model of wear debris-induced osteolysis. Gene Ther 2004, 11:483-491.

32. Wimhurst JA, Brooks RA, Rushton N: Inflammatory responses of human primary macrophages to particulate bone cements in vitro. J Bone Joint Surg (Br) 2001, 83:278-282.

33. Golub LM, Lee HM, Greenwald RA, Ryan ME, Sorsa T, Salo T, Giannobile WV: A matrix metalloproteinase inhibitor reduces bone-type collagen degradation fragments and specific collagenases in gingival crevicular fluid during adult periodontitis. Inflamm Res 1997, 46:310-319.

34. Yamada $Y$, Ando F, Niino N, Shimokata H: Association of a polymorphism of the matrix metalloproteinase-1 gene with bone mineral density. Matrix Biol 2002, 21:389-392.

35. Dunleavey L, Beyzade S, Ye S: Rapid genotype analysis of the matrix metalloproteinase- 1 gene $1 \mathrm{G} / 2 \mathrm{G}$ polymorphism that is associated with risk of cancer. Matrix Biol 2000, 19:175-177.

36. Holliday LS, Welgus HG, Fliszar CJ, Veith GM, Jeffrey JJ, Gluck SL: Initiation of osteoclast bone resorption by interstitial collagenase. J Biol Chem 1997, 272:22053-22058.

37. Vincenti MP, White LA, Schroen DJ, Benbow U, Brinckerhoff CE: Regulating expression of the gene for matrix metalloproteinase-1 (collagenase): mechanisms that control enzyme activity, transcription, and mRNA stability. Crit Rev Eukaryot Gene Expr 1996, 6:391-411.

38. Li TF, Santavirta S, Virtanen I, Kononen M, Takagi M, Konttinen YT: Increased expression of EMMPRIN in the tissue around loosened hip prostheses. Acta Orthop Scand 1999, 70:446-451.

39. Imai $S$, Konttinen $Y T$, Jumppanen $M$, Lindy $O$, Ceponis A, Kemppinen $P$ Sorsa T, Santavirta S, Xu JW, Lopez-Otin C: High levels of expression of collagenase-3 (MMP-13) in pathological conditions associated with a foreign-body reaction. J Bone Joint Surg (Br) 1998, 80:701-710.

40. Malik MH, Jury F, Bayat A, Ollier WE, Kay PR: Genetic susceptibility to total hip arthroplasty failure: a preliminary study on the influence of matrix metalloproteinase 1, interleukin 6 polymorphisms and vitamin D receptor. Ann Rheum Dis 2007, 66:1116-1120.

41. Ray JM, Stetler-Stevenson WG: The role of matrix metalloproteases and their inhibitors in tumour invasion, metastasis and angiogenesis. Eur Respir J 1994, 7:2062-2072.

\section{Submit your next manuscript to BioMed Central and take full advantage of:}

- Convenient online submission

- Thorough peer review

- No space constraints or color figure charges

- Immediate publication on acceptance

- Inclusion in PubMed, CAS, Scopus and Google Scholar

- Research which is freely available for redistribution

Submit your manuscript at www.biomedcentral.com/submit
C Biomed Central 